\title{
The Impact of Challenge Stress on the Innovative Behavior of Scientific Researchers in Universities: Moderating Effect of Goal Orientation
}

\author{
Yu Zhang* Xiaobao Peng \\ School of Public affairs, University of Science and Technology of China, 96 Jinzhai Road, Hefei 230026, China
}

\begin{abstract}
In the context of China, this study discusses the influence of challenge stress on the innovative behavior of scientific researchers in universities and moderating effect of goal orientation. Specifically, We contend that a positive relationship exists between challenge stress and innovative behavior of scientific researchers in universities. The goal orientation includes learning goal orientation, proving goal orientation, and avoiding goal orientation. Learning goal orientation and proving goal orientation positively moderate the relationship between challenge stress and innovative behavior of scientific researchers in universities, whereas avoiding goal orientation negatively moderates the relationship between them. The empirical findings support our hypotheses.
\end{abstract}

Keywords: challenge stress, goal orientation, innovative behaviour, scientific researchers, universities

DOI: $10.7176 / \mathrm{EJBM} / 11-11-10$

Publication date: April $30^{\text {th }} 2019$

\section{Introduction}

Under the background of China's innovative country construction and "Double Tops" construction, the country and universities have higher expectations and requirements for scientific researchers. Scientific researchers in universities shoulder the important responsibility of cultivating innovative talents, promoting technological innovation and the commercialization of research findings. The play the dual role of teachers and researchers in their work. The innovative behavior of scientific researchers will largely determine the quality of university construction, the cultivation of innovative talents, and the improvement of national scientific and technological strength. At present, the competition for scientific and technological innovation among countries is becoming increasingly fierce. We must pay attention to and encourage the innovative behavior of university researchers, give full play to the advantages of scientific researchers in universities, and enhance the national scientific and technological competitiveness.

Most of the previous researches on individual innovation behavior mainly focused on business managers or employees, while there were few studies focusing on public management. At the same time, many researches on individual innovation behavior focus on organizational innovation atmosphere, team members, leadership style, personal traits and other factors(Sethia, 1989, Pirola-Merlon, 2004; Wu, 2014), and less on the impact of work requirements and task characteristics on individual innovation behavior. Previous studies have examined the impact of work stress on individual innovation behavior, but the conclusions of the study are still controversial (Amabile, 1996; Shalley, 2000; Ohly \& Fritz, 2010). Therefore, this paper will draw on the challenge and hindrance stress concept proposed by Cavanaugh et al. (2000) to further discuss the impact of work stress on the innovative behavior of scientific researchers in universities.

Different kinds of stress will have different effects on individual innovation behavior. According to previous researches, the negative influence of hindrance stress on individual innovation behavior has been widely recognized(Sacramento, 2013; He, 2014), but due to the inconsistent research background, studies on the impact of challenge stress on individual innovation behavior have not yet reached consensus (Baer \& Oldham, 2006; Lin et al., 2015; Ohly \& Fritz, 2010; Sacramento et al., 2013). In general, challenge stress refers to time pressure at work, overloaded work, more job responsibilities (McCauley et al., 1994; Cavanaugh, 2000). These challenging job requirements and work environments can motivate individuals to generate positive emotions, as well as creates challenge and feelings of fulfillment or achievement(Selye, 1984; Cavanaugh, 2000), which can promote their innovative behavior. For scientific researchers, they have both teaching and researching responsibilities and may face more challenge stress. These challenge stress may have an important impact on the innovative behavior of scientific researchers in universities. Therefore, it is necessary for us to discuss the relationship between the two. In addition, previous studies have shown that goal orientation influences an individual's emotional, behavioral, and cognitive responses in the environment (Butler, 1992; Dweck \& Leggett, 1988). According to VandeWalle (1997), we will divide the goal orientation into learning goal orientation, proving goal orientation, and avoiding goal orientation, and discuss their different influences on the relationship between challenge stress and the innovative behavior of scientific researchers in universities.

Our study makes two major contributions. First, scholars' empirical research on individual innovation behavior were mainly concentrated in the field of enterprise management. This paper develops the research scope 
into the field of public management, pays attention to the influencing factors and intrinsic mechanism of scientific researchers' innovation behavior. To a certain extent, we have further enriched and improved the research on individual innovation behavior, which has certain theoretical significance. Second, there are still inconsistencies in the impact of challenge stress on individual innovation behavior. And the existing literature lacks the study of challenge stress in the Chinese context. We will be committed to studying the impact of challenge stress on the innovative behavior of scientific researchers in the Chinese universities context, which may enrich the challenge and hindrance stress theory research to a certain extent.

\section{Theory and Hypotheses}

\subsection{Challenge stress on the innovative behavior}

Scientific researchers in universities is one of the main forces in implementing China's innovation strategy. On the one hand, they shoulder the heavy responsibility of rejuvenating the country through science and education, and need to complete teaching tasks with strong frontier and creativity in order to cultivate high-level talents for the country. On the other hand, they need to have strong academic ability and innovative ability to complete scientific research tasks so as to lay the foundation for national scientific progress. The innovative requirements of teaching and research work and the complexity of work make scientific researchers face various challenge stress. They have more responsibilities in scientific research, such as applying for many projects, publishing high-level academic papers, and completing the transformation of scientific and technological achievements. These heavy scientific research tasks generally have strict performance assessment, and the objectives and time periods of the assessment will cause certain challenges to the scientific researchers. In addition, different types of research and teaching tasks often need to be carried out at the same time, which leads scientific researchers to take on more job responsibilities and face more challenge stress. Crawford (2010) argued that challenge stress is beneficial to individual growth and can trigger their positive emotions that have a significant impact on their creativity (Oldham, 2003). Such positive emotions triggered by challenge stress can creates challenge and feelings of fulfillment or achievement(Selye, 1984; Cavanaugh, 2000), while increase the breadth and depth of their attention, thereby promoting individuals to abandon old schemes and pursue newer ways to solve problems (Fredrikson, 2003). At the same time, individuals in a positive emotional state are more likely to establish connections between different stimuli (Isen, 1999), which allows scientific researchers to better integrate resources in the face of challenge stress, to constantly seek new ideas for research and teaching, and to work hard to put them into practice. This will encourage scientific researchers to increase the possibility of implementing innovative behaviors in project, papers, and teaching. In addition, when individuals interact with their surroundings, they initiate cognitive assessments and change assessments based on changes in the environment (Crocker, et. a1, 2003). A benign environment will allow individuals to make positive assessments and willing to spend time solving problems. This will inspire their creative thinking and actively engage in innovative practices. For scientific researchers in universities, once they overcome the stress of completing the projects, academic papers, and teaching tasks, they will be more likely to receive high-yield returns, such as bonus acquisition, position and title promotion, high academic reputation, personal value realization and so on. At this point, scientific researchers will treat research and teaching as meaningful and valuable things that will lead to higher motivations for their work (Lawler \& Hall, 1970; Hackman \& Lawler, 1971; Boswell, 2004). In such cases, they will increase their curiosity, be willing to try new ways of working, and participate in high-risk innovation activities to solve work problems, thereby further enhancing their level of innovation (Baer \& Oldham, 2006). Thus, we offer the following hypothesis:

H1: Challenge stress is positively related to the innovative behavior of scientific researchers in universities.

\subsection{Moderating effect of Learning goal orientation}

Generally speaking, individuals with high learning goal orientation have positive cognitive emotions and reaction patterns. They hope to achieve self-development by learning new skills, mastering new situations, and improving their own abilities (VandeWalle, 1997), and they tend to attribute their success to their own tireless efforts. Scientific researchers in universities face challenge stress, such as time pressure, overload work about projects, research and teaching responsibilities. Such stress is something they can overcome through their efforts and bring them benefits and rewards. Under such circumstances, the challenge and positive emotions of scientific researchers will be stimulated, so that they are actively engaged in work and implement innovative behavior. If scientific researchers have the high learning goal orientation at this time, they will be more likely to invest in innovative practices of research and teaching. There are mainly the following reasons. First, individuals with a high learning goal orientation can demonstrate a continuous learning spirit during their work (Dweck, 2013), and they will spend more time acquiring information about new knowledge or new skills than others (Kozloski et al., 2001; Seijts \& Latham, 2006). A focus on continuous learning equips scientific researchers with the knowledge and skills to cope with challenge stress and tasks (Elliot \& Mc Gregor, 2001), which makes it easier for them to deal with challenge stress and work actively, and further inspire their creative passion and innovative behavior. Second, individuals with high learning goal orientation will increase their job involvement and constantly seek challenging tasks due 
to their desire for new knowledge and skills (Elliot \& McGregor, 2001). This will motivate scientific researchers to cope with challenge stress. They will not worry about the time stress and overwork caused by research and teaching tasks, but will generate internal motivations for positive response. At this time, learning goal orientation and internal motivation will promote each other (Hirst et al., 2009), encouraging scientific researchers to obtain more opportunities, generate more new ideas and achieve more innovative behaviors in work (Amabile, 1996). Thus, we predict that

$\mathrm{H} 2$ : The learning goal orientation moderates the relationship between challenge stress and innovative behavior of scientific researchers in universities. A higher learning goal orientation enhances the positive relationship between them.

\subsection{Moderating effect of Proving goal orientation}

Individuals with high proving goal orientation tend to prove their abilities to others by completing tasks and hope to get positive comments from others (VandeWalle, 1997; VanYperen, 2003). They are motivated by higher performance rather than intrinsic interest. When scientific researchers have a high level of proving goal orientation, they may try to overcome the challenge stress to implement innovative behaviors in order to achieve their research and teaching performance goals. There are several reasons. First, under the background that the country and universities increasingly attach importance to the innovation ability of scientific researchers, the implementation of innovation behavior has become an important channel for them to obtain performance and prove their ability. Although scientific researchers with high proving goal orientation face great challenge stress, such stress is generally within the controllable range of individuals and they have strong motivation to work hard(Sideridis, 2005), which will urge them to actively deal with the challenge stress in scientific research and teaching tasks, put themselves more into work, and initiate feasible innovation schemes and practices to prove their strong innovation ability, so as to win the positive evaluation of the organization or the superior. Second, individuals with high proving goal orientation often prove their abilities by comparing with others and hope to prove their value by seeking feedback from others (Vande Walle, 1997). When scientific researchers face great challenge stress, on the one hand, they will take the initiative to seek work-related feedback from their superiors or colleagues to improve their work, so as to discover and implement new ideas (Zhou, 1998); on the other hand, they may actively share knowledge and information with others to enhance individual reputation (Swift et al., 2010), which further promotes the dissemination of innovative thinking and facilitates the innovative behavior of scientific researchers in universities (Armbrecht et al., 2001). Hence, we offer the following hypothesis:

H3: The proving goal orientation moderates the relationship between challenge stress and innovative behavior of scientific researchers in universities. A higher proving goal orientation enhances the positive relationship between them.

\subsection{Moderating effect of Avoiding goal orientation}

Individuals with high avoiding goal orientation tend to avoid exposing their deficiencies and hope to minimize the negative evaluations of others. They rarely participate in activities that help them improve their abilities (VandeWalle, 1997), and often setting low-level goals for themselves in order to increase the likelihood of success (Elliot, 1999). Scientific researchers in universities face many challenge stress from research and teaching requirements in their work. In general, such stress can inspire challenge and a sense of accomplishment, and bring positive emotions to them, through which they will be actively engaged in innovative work. However, if scientific researchers have high avoiding goal orientation, challenge stress will not exert positive effects, and may also cause individual anxiety, which is not conducive to the emergence of innovative behavior. There are mainly the following reasons. First, individuals with high avoiding goal orientation are afraid to accept challenges. They worry that task failure will expose their lack of ability and bring negative evaluations to themselves. It makes them tend to avoid challenges and difficulties (Button, 1996; Naidoo et al., 2012). They may reluctant to actively deal with challenging pressure and implement high-risk innovative behaviors, and even feel helpless and anxious in the face of stress. In this case, challenge stress is difficult to play a positive role in the innovative behavior of scientific researchers, and even inhibit innovation. Second, individuals with high avoiding goal orientation often believe that their abilities cannot be changed, even if efforts are made, it will only prove their incompetence (Dweck, 1988). Therefore, when faced with great challenge stress, scientific researchers who have high avoiding goal orientation may think that their ability is not enough to effectively deal with these stress and implement innovative behavior. This avoidance tendency may have a negative impact on innovative behavior of scientific researchers in universities. Therefore, we proposes the following assumptions:

H4: The avoiding goal orientation moderates the relationship between challenge stress and innovative behavior of scientific researchers in universities. A higher avoiding goal orientation weakens the positive relationship between them. 


\section{Method}

\subsection{Samples and Data Collection}

The main body of scientific researchers in universities is university teachers, who are quite different from ordinary corporate employees. Scientific researchers in universities not only shoulder the heavy responsibility of cultivating high-level innovative talents for the country, but also must bear major responsibility for academic innovation and scientific and technological achievements transformation, which puts great demands on the innovation of their teaching and research work. The study of their innovation behavior is of great significance. In this paper, scientific researchers in universities, that is, the teachers engaged in scientific research activities in universities, are the main research objects. The survey areas mainly include Beijing, Shanghai, Zhejiang, Anhui, Jiangsu and other provinces and cities. The reason is that these cities not only have a good research and education environment, but also have frequent innovation activities and fierce innovation competition. In such an environment, the innovative behavior of scientific researchers in universities is more likely to be highlighted.

The current study collected data through paper and electronic questionnaires. In our survey, we sent a total of 300 questionnaires and returned 267 of them. After eliminating invalid questionnaires with incomplete data or data errors, 233 valid questionnaires were obtained, and the validity rate reached $77.67 \%$. In our sample, the participating scientific researchers in universities $62.66 \%$ were male, and $37.34 \%$ were female, with most of them aged $31-40$ and 41-50, accounting for approximately $47.64 \%$ and $39.06 \%$.

\subsection{Measures}

Individual innovation behavior. Scott and Bruce (1994) developed a six-item scale for individual innovation behavior in their research. The scale has been widely recognized by scholars at home and abroad, and many empirical studies have proved that the scale has high reliability and validity. Therefore, this paper draws on the scale developed by Scott and Bruce (1994) and uses the Likert five-point scale for measurement. 1 means "very disagree" and 5 means "very agree". The higher the final score, the stronger the innovative behavior of scientific researchers in universities.

Challenge stress. Our paper mainly uses the scale developed by Cavanaugh et al. (2000) to measure the challenge stress, which has been widely recognized and used in domestic and foreign research. The challenge stress consists of six items, which are also measured using the Likert five-point scale. The higher the final score, the greater challenge stress faced by scientific researchers in universities.

Goal orientation. VandeWalle (1997) proposed the three-dimensional structure and measurement method of goal orientation based on the analysis of the previous scholars' viewpoints. This is a relatively mature and widely used research result. We use the 13-item scale developed by VandeWalle (1997) to measure the goal orientation. Among them, there are 5 items of learning goal orientation, 4 items of proving goal orientation and 4 items of avoiding goal orientation. We also use the Likert five-point scale for measurements.

Control variables. According to previous studies, some demographic variables (such as gender, age, education level, etc.) will affect individual innovation behavior to some extent (Mumford \& Gustafson, 1988; Zhou \& George, 2001; Ohly, Sonnentag, \& Pluntke, 2006). Therefore, we use these variables as control variables to greatly reduce the potential risk of the research model. In addition, we think that the marital status and professional technical title of scientific researchers in universities will also have an impact on their innovative behavior, and also should be used as a control variables.

\section{Analysis and results}

Table 1 shows the descriptive statistics and Pearson's correlation of all variables examined in this study. The correlations of most of the variables in our study are low in magnitude (i.e., b 0.40), it has little impact on our analysis. We also did a multicollinearity test. The general method for judging multicollinearity is to test whether the variance inflation factors (VIF) is greater than 10 . We calculated the VIF value for each of the regression equation. The highest VIF value is 1.567 , which is well below the recommended level of 10 , this indicates that there is no problem of multicollinearity. Moreover, the values of Cronbach's $\alpha$ are higher than 0.7 , indicating that the scales of each variable have good internal consistency and meet the requirements for further processing. The Kaiser-Meyer-Olkin is 0.817; the significance of Bartlett's is 0.00 , below 0.05, indicating good validity. In addition, common method bias can affect many social science studies and cause significant disputes (Doty \& Glick, 1998). Harmen's one-factor test was performed to check the common method bias. The variance contribution rate of the first unrotated factor is $25.901 \%$, indicating that the issue of common method bias is not serious. 
Table 1. Descriptive Statistics and Pearson Correlations Among the Variables

\begin{tabular}{|c|c|c|c|c|c|c|c|c|c|c|c|}
\hline Variables & Mean & s.d. & 1 & 2 & 3 & 4 & 5 & 6 & 7 & 8 & 9 \\
\hline 1. Gender & 0.630 & 0.485 & & & & & & & & & \\
\hline 2. Age & 2.500 & 0.720 & -.004 & & & & & & & & \\
\hline $\begin{array}{l}\text { 3. Marital } \\
\text { status }\end{array}$ & 0.570 & 0.497 & $-.228 * *$ & $.322 * *$ & & & & & & & \\
\hline $\begin{array}{l}\text { 4. Education } \\
\text { level }\end{array}$ & 2.720 & 0.512 & $-.144 *$ & $-.273 * *$ & $-.172 * *$ & & & & & & \\
\hline $\begin{array}{l}\text { 5.Professional } \\
\text { technical } \\
\text { titles }\end{array}$ & 2.770 & 0.875 & .029 & $-.170 * *$ & $-.163 *$ & $.538 * *$ & & & & & \\
\hline $\begin{array}{l}\text { 6. Challenge } \\
\text { stress }\end{array}$ & 3.419 & 0.739 & -.022 & -.037 & -.029 & .081 & .018 & & & & \\
\hline $\begin{array}{l}\text { 7.Learning } \\
\text { goal } \\
\text { orientation }\end{array}$ & 3.331 & 0.881 & .018 & .125 & -.015 & -.048 & .044 & $-.142 *$ & & & \\
\hline $\begin{array}{l}\text { 8.Proving } \\
\text { goal } \\
\text { orientation }\end{array}$ & 3.230 & 0.736 & .006 & $.146^{*}$ & .035 & -.004 & .078 & .006 & $.538 * *$ & & \\
\hline $\begin{array}{l}\text { 9.Avoiding } \\
\text { goal } \\
\text { orientation }\end{array}$ & 2.899 & 0.733 & -.119 & .068 & -.067 & -.032 & $-.138 *$ & .073 & $-.217 * *$ & $-.135 *$ & \\
\hline $\begin{array}{l}\text { 10.Individual } \\
\text { innovation } \\
\text { behavior }\end{array}$ & 3.471 & 0.799 & -.084 & $-.148^{*}$ & $-.182 * *$ & .066 & .084 & $.182 * *$ & $.302 * *$ & $.269 *$ & $-.140 *$ \\
\hline
\end{tabular}

$* \mathrm{p}<.05, * * \mathrm{p}<.01$

Table 2 shows the results of the regression analyses. Model 1 analyzes all the control variables, including gender, age, marital status, education level, and professional technical titles of scientific researchers in universities. The regression results showed that the gender $(\beta=-0.134, p<0.050)$ and marital status $(\beta=-0.180, p<0.050)$ of scientific researchers were negatively related to innovative behavior of scientific researchers in universities. In Models 2, we add our independent variable. As predicted, the coefficient of challenge stress is positive and significant $(\beta=0.174, p<0.010)$. The result supports H1 that challenge stress has a positive relationship with innovative behavior of scientific researchers in universities. Models 3 and Models 4 examine the moderating effects of learning goal orientation. In Model 3, we add learning goal orientation. Model 4 includes the interaction between learning goal orientation and challenge stress. Based on Model 4, learning goal orientation moderates the positive relationship between challenge stress and innovative behavior of scientific researchers in universities $(\beta=$ $0.196, \mathrm{p}<0.010)$. Therefore, $\mathrm{H} 2$ is supported. Model 5 and Model 6 examine the moderating effects of proving goal orientation. In Model 5, we add proving goal orientation. Model 6 includes the interaction between proving goal orientation and challenge stress. Based on Model 6, proving goal orientation moderates the positive relationship between challenge stress and innovative behavior of scientific researchers in universities $(\beta=0.130, p$ $<0.050$ ). Thus, $\mathrm{H} 3$ is supported. Model 7 and Model 8 examine the moderating effects of avoiding goal orientation. In Model 7, we add avoiding goal orientation. Model 8 includes the interaction between avoiding goal orientation and challenge stress. Based on Model 8, avoiding goal orientation moderates the positive relationship between challenge stress and innovative behavior of scientific researchers in universities $(\beta=-0.160, p<0.050)$. Thus, H4 is supported. 
Table 2. Results of Regression Analyses of Innovative Behavior of Scientific Researchers in Universities

\begin{tabular}{|c|c|c|c|c|c|c|c|c|}
\hline Variables & $\begin{array}{c}\text { Model } \\
1\end{array}$ & Model 2 & Model 3 & Model 4 & Model 5 & Model 6 & Model 7 & Model 8 \\
\hline Gender & $-.134 *$ & $-.132 *$ & $-.128 *$ & $-.136^{*}$ & $-.131 *$ & $-.133^{*}$ & $-.157^{*}$ & $-.148^{*}$ \\
\hline Age & -.091 & -.089 & $-.137 *$ & $-.138 *$ & $-.136^{*}$ & $-.120 \dagger$ & -.072 & -.067 \\
\hline Marital status & $-.180 *$ & $-.177 *$ & $-.156^{*}$ & $-.171 * *$ & $-.177 * *$ & $-.201 * *$ & $-.204 * *$ & $-.215 * *$ \\
\hline Education level & -.045 & -.061 & -.040 & -.052 & -.054 & -.043 & -.057 & -.041 \\
\hline Professional technical titles & .067 & .074 & .041 & .057 & .039 & .048 & .046 & .039 \\
\hline Challenge stress & & $.174 * *$ & $.221 * * *$ & $.193 * * *$ & $.171 * *$ & $.152 *$ & $.186^{* *}$ & $.161 *$ \\
\hline Learning goal orientation & & & $.347 * * *$ & $.360 * * *$ & & & & \\
\hline $\begin{array}{l}\text { Learning goal orientation*Challenge } \\
\text { stress }\end{array}$ & & & & $.196 * *$ & & & & \\
\hline Proving goal orientation & & & & & $.292 * * *$ & $.292 * * *$ & & \\
\hline $\begin{array}{l}\text { Proving goal orientation* Challenge } \\
\text { stress }\end{array}$ & & & & & & $.130 *$ & & \\
\hline Avoiding goal orientation & & & & & & & $-.177 * *$ & $-.185 * *$ \\
\hline $\begin{array}{l}\text { Avoiding goal orientation* Challenge } \\
\text { stress }\end{array}$ & & & & & & & & $-.160 *$ \\
\hline$R^{2}$ & .060 & .090 & .205 & .242 & .173 & .188 & .120 & .144 \\
\hline Adjust $R^{2}$ & .040 & .066 & .181 & .215 & .147 & .159 & .092 & .114 \\
\hline$F$ & $2.910 *$ & $3.737 * * *$ & $8.309 * * *$ & $8.949 * * *$ & $6.702 * * *$ & $6.496 * * *$ & $4.370 * * *$ & $4.724 * * *$ \\
\hline
\end{tabular}

\section{Discussion and conclusion}

In the context of China, our study discussed the relationship between challenge stress and innovative behavior of scientific researchers in universities. According to the research of VandeWalle (1997), we divide the goal orientation into three dimensions: learning goal orientation, proving goal orientation and avoiding goal orientation, and discuss their moderating effect on the relationship between challenge stress and innovative behavior of scientific researchers in universities. The empirical analysis showed that challenge stress is positively related to the innovative behavior of scientific researchers in universities; Learning goal orientation and proving goal orientation have positive moderating effect on the relationship between challenge stress and innovative behavior of scientific researchers in universities; while avoiding goal orientation has negative moderating effect on the relationship between challenge stress and innovative behavior of scientific researchers in universities.

As the key force for cultivating innovative talents and carrying out scientific and technological innovations, scientific researchers' innovative behaviors in teaching and scientific research will have an important impact on universities and even the country's future innovative development. Scientific researchers in universities are not only faced with heavy scientific research tasks, but also shoulder the teaching work. The innovative requirements of each job put them at greater challenge stress than the ordinary enterprise staff. From this perspective, it is necessary to study the impact of challenge stress on innovative behavior of scientific researchers in universities. Our research showed that challenge stress can promote the innovative behavior of scientific researchers in universities. The challenge stress faced by scientific researchers in the process of scientific research and teaching, such as the pressure of scientific research time, the overloading of projects, and the responsibility for scientific research and teaching, are the obstacles they can overcome through hard work and can bring certain returns. These can motivate researchers to generate positive emotions and challenge desires, thus stimulating their creative thinking and innovative practices. Therefore, universities need to make certain improvements in work requirements, performance appraisal and other aspects, increase the challenge stress moderately, and provide scientific researchers with a good innovation environment for scientific research and teaching.

Our paper also discussed the moderating of effect goal orientation the relationship between challenge stress and innovative behavior of scientific researchers in universities. The results of the study indicated that the learning goal orientation have positive moderating effect on the relationship between challenge stress and innovative behavior of scientific researchers in universities. In other words, the scientific researcher's learning goal orientation and challenge stress have strong complementary effects. When scientific researchers face great challenge stress, individuals with high learning goal orientation, tend to overcome stress and complete challenging and innovative tasks because of their desire for new knowledge and skills, which will inspire their innovative behavior. In addition, proving goal orientation also have positive moderating effect on the relationship between challenge stress and innovative behavior of scientific researchers in universities, but its effect on the relationship is slightly less than that of learning goal orientation. Scientific researchers with high proving goal orientation are eager to prove their abilities to others and get positive comments from others. Since the implementation of innovative behavior is an important channel for them to obtain performance and prove their ability, they will have stronger motivation to cope with challenge stress and implement innovative behaviors. However, our results showed that avoiding goal orientation has negative moderating effect on the relationship between challenge stress and innovative behavior of scientific researchers in universities. In order to avoid exposing their own shortcomings 
and minimize the negative evaluation of others, scientific researchers with high avoiding goal orientation will be reluctant to actively respond to challenge stress and implement high-risk innovative behaviors, which will pose a great threat to innovation. Therefore, scientific researchers in universities should change their concepts in the course of their work, focus on cultivating learning goal orientation and proving goal orientation, try to adjust their mentality to change their avoiding goal orientation, through which they may better implement innovative behaviors in research and teaching practice.

In addition, we believe that the effects of proving goal orientation and challenge stress on the innovative behaviors of scientific researchers in universities may be different from those of other ordinary employees. Our research results showed that proving goal orientation will have complementary effects with challenge stress and positively effects the innovative behavior of scientific researchers in universities. Due to the special nature of universities, scientific researchers in universities not only need to have strong academic foresight to cultivate more high-level talents, but also need to complete the scientific research tasks such as projects, academic papers, and the transformation of scientific and technological achievements. Whether it is teaching or scientific research, scientific researchers must have a high sense of innovation and ability to effectively achieve the desired goals. Innovative work results have also become an important indicator of performance evaluation in universities. In this case, scientific researchers with high proving goal orientation will actively respond to the challenge stress and devote themselves to work in order to achieve outstanding performance goals and prove their ability. It will enhances the positive emotions and sense of accomplishment that come with challenge stress, which in turn increases their likelihood of implementing innovative behaviors. However, employees in ordinary enterprises generally complete some daily affairs, and the organization's requirements for their innovation are less than those of universities. When faced with challenge stress, they tend to choose jobs with low difficulty, hoping to show good performance and prove themselves in an easier way (Steele-Johnson, 2000), while for complex tasks requiring new knowledge and skills, such as innovation, they may be unable to cope with the stress and show low performance (Ford,1998). Therefore, when facing challenge stress and innovative work, scientific researchers and ordinary enterprise employees with proving goal orientation may have differentiated behaviors.

Our study has limitations, thus providing several issues for future research. First, our paper studied the impact of challenge stress on the innovative behavior of scientific researchers in universities, which has certain significance. However, scientific researchers often face both challenge and hindrance stress. Future research can incorporate hindrance stress into the research framework and discuss the different impacts of the two on the innovative behavior of scientific researchers in universities. Second, we obtain data by randomly distributing questionnaires to the research objects, which is reasonable to some extent. But we also need to recognize that the challenge stress at work are constantly changing, and goal orientations of individuals are dynamically adjusted over time and environmental changes, which may have an impact on individual innovation behavior. Therefore, future research can focus on the dynamic changes of challenge stress and goal orientation, using panel data for research and analysis. Third, our paper mainly discussed the influencing factors of innovative behaviors of scientific researchers in the Chinese context. However, under different cultural backgrounds, the job responsibilities of scientific researchers may be different, and their perceptions of stress may also differ. Therefore, future research can expand the research on the innovative behavior of scientific researchers in universities to other different cultural backgrounds, and compare the influence differences of challenge stress on innovative behavior of scientific researchers in a variety of cultural contexts.

\section{References}

Amabile, T. M., Conti, R., Coon, H., Lazenby, J., \& Herron, M. (1996). Assessing the work environment for creativity. Academy of management journal, 39(5), 1154-1184.

Armbrecht Jr, F. R., Chapas, R. B., Chappelow, C. C., Farris, G. F., Friga, P. N., Hartz, C. A., ... \& Whitwell, G. E. (2001). Knowledge management in research and development. Research Technology Management, 28-48.

Baer, M., \& Oldham, G. R. (2006). The curvilinear relation between experienced creative time pressure and creativity: moderating effects of openness to experience and support for creativity. Journal of Applied Psychology, 91(4), 963.

Boswell, W. R., Olson-Buchanan, J. B., \& LePine, M. A. (2004). Relations between stress and work outcomes: The role of felt challenge, job control, and psychological strain. Journal of Vocational Behavior, 64(1), 165181.

Butler, R. (1992). What young people want to know when: Effects of mastery and ability goals on interest in different kinds of social comparisons. Journal of Personality and Social Psychology, 62(6), 934.

Button, S. B., Mathieu, J. E., \& Zajac, D. M. (1996). Goal orientation in organizational research: A conceptual and empirical foundation. Organizational behavior and human decision processes, 67(1), 26-48.

Cavanaugh, M. A., Boswell, W. R., Roehling, M. V., \& Boudreau, J. W. (2000). An empirical examination of selfreported work stress among US managers. Journal of applied psychology, 85(1), 65.

Crawford, E. R., LePine, J. A., \& Rich, B. L. (2010). Linking job demands and resources to employee engagement 
and burnout: a theoretical extension and meta-analytic test. Journal of applied psychology, 95(5), 834.

Crocker, J., Luhtanen, R. K., Cooper, M. L., \& Bouvrette, A. (2003). Contingencies of self-worth in college students: theory and measurement. Journal of personality and social psychology, 85(5), 894.

Doty, D. H., \& Glick, W. H. (1998). Common methods bias: does common methods variance really bias results?. Organizational research methods, 1(4), 374-406.

Dweck, C. S., \& Leggett, E. L. (1988). A social-cognitive approach to motivation and personality. Psychological review, 95(2), 256.

Dweck, C. S. (2013). Self-theories: Their role in motivation, personality, and development. Psychology press.

Elliot, A. J. (1999). Approach and avoidance motivation and achievement goals. Educational psychologist, 34(3), 169-189.

Elliot, A. J., \& McGregor, H. A. (2001). A $2 \times 2$ achievement goal framework. Journal of personality and social psychology, 80(3), 501.

Ford, J. K., Smith, E. M., Weissbein, D. A., Gully, S. M., \& Salas, E. (1998). Relationships of goal orientation, metacognitive activity, and practice strategies with learning outcomes and transfer. Journal of applied psychology, 83(2), 218.

Fredrikson, M., \& Furmark, T. (2003). Amygdaloid regional cerebral blood flow and subjective fear during symptom provocation in anxiety disorders. Annals of the New York Academy of Sciences, 985(1), 341-347.

Hackman, J. R., \& Lawler, E. E. (1971). Employee reactions to job characteristics. Journal of applied psychology, $55(3), 259$.

He, W. Y., Pi, H., \& Wang, N. (2014). The Effect of Challenge-Hindrance Stressor on Engineering Design Innovation Behavior-The Mediating Role of Intrinsic Motivation. In Applied Mechanics and Materials (Vol. 584, pp. 2668-2671). Trans Tech Publications.

Hirst, G., Van Knippenberg, D., \& Zhou, J. (2009). A cross-level perspective on employee creativity: Goal orientation, team learning behavior, and individual creativity. Academy of management journal, 52(2), 280293.

Isen, A. M. (1999). On the relationship between affect and creative problem solving. Affect, creative experience, and psychological adjustment, 3, 17.

Kozlowski, S. W., Gully, S. M., Brown, K. G., Salas, E., Smith, E. M., \& Nason, E. R. (2001). Effects of training goals and goal orientation traits on multidimensional training outcomes and performance adaptability. Organizational behavior and human decision processes, 85(1), 1-31.

Lawler, E. E., \& Hall, D. T. (1970). Relationship of job characteristics to job involvement, satisfaction, and intrinsic motivation. Journal of Applied psychology, 54(4), 305.

Lin, W., Ma, J., Wang, L., \& Wang, M. (2015). A double-edged sword: The moderating role of conscientiousness in the relationships between work stressors, psychological strain, and job performance. Journal of Organizational Behavior, 36(1), 94-111.

McCauley, C. D., Ruderman, M. N., Ohlott, P. J., \& Morrow, J. E. (1994). Assessing the developmental components of managerial jobs. Journal of applied psychology, 79(4), 544.

Mumford, M. D., \& Gustafson, S. B. (1988). Creativity syndrome: Integration, application, and innovation. Psychological bulletin, 103(1), 27.

Naidoo, L. J., DeCriscio, A., Bily, H., Manipella, A., Ryan, M., \& Youdim, J. (2012). The $2 \times 2$ model of goal orientation and burnout: The role of approach-avoidance dimensions in predicting burnout. Journal of applied social psychology, 42(10), 2541-2563.

Oldham, G. R. (2003). Stimulating and supporting creativity in organizations. Managing knowledge for sustained competitive advantage, 243-273.

Ohly, S., \& Fritz, C. (2010). Work characteristics, challenge appraisal, creativity, and proactive behavior: A multilevel study. Journal of Organizational Behavior, 31(4), 543-565.

Ohly, S., Sonnentag, S., \& Pluntke, F. (2006). Routinization, work characteristics and their relationships with creative and proactive behaviors. Journal of Organizational Behavior: The International Journal of Industrial, Occupational and Organizational Psychology and Behavior, 27(3), 257-279.

Pirola-Merlo, A., \& Mann, L. (2004). The relationship between individual creativity and team creativity: Aggregating across people and time. Journal of Organizational behavior, 25(2), 235-257.

Sacramento, C. A., Fay, D., \& West, M. A. (2013). Workplace duties or opportunities? Challenge stressors, regulatory focus, and creativity. Organizational Behavior and Human Decision Processes, 121(2), 141-157.

Scott, S. G., \& Bruce, R. A. (1994). Determinants of innovative behavior: A path model of individual innovation in the workplace. Academy of management journal, 37(3), 580-607.

Seijts, G. H., \& Latham, G. P. (2006). Learning Goals or Performance Goals: is it the Journey or the Destination?'. Ivey Business Journal, 70(5), 1-6.

Selye, H. (1984). History and present status of the stress concept. In. L. Goldberger \& M. Breznit (eds) Handdbook os stress. Theoretical and Clinical Aspects. 
Sethia, N.K. (1989),“The shaping of creativity in organizations”,Academy of Management Proceedings, pp. 224228.

Shalley, C. E., Gilson, L. L., \& Blum, T. C. (2000). Matching creativity requirements and the work environment: Effects on satisfaction and intentions to leave. Academy of management journal, 43(2), 215-223.

Sideridis, G. D. (2005). Goal Orientation, Academic Achievement, and Depression: Evidence in Favor of a Revised Goal Theory Framework. Journal of educational psychology, 97(3), 366.

Swift, M., Balkin, D. B., \& Matusik, S. F. (2010). Goal orientations and the motivation to share knowledge. Journal of Knowledge Management, 14(3), 378-393.

Steele-Johnson, D., Beauregard, R. S., Hoover, P. B., \& Schmidt, A. M. (2000). Goal orientation and task demand effects on motivation, affect, and performance. Journal of Applied psychology, 85(5), 724.

VandeWalle, D. (1997). Development and validation of a work domain goal orientation instrument. Educational and psychological measurement, 57(6), 995-1015.

Van Yperen, N. W. (2003). Task interest and actual performance: the moderating effects of assigned and adopted purpose goals. Journal of personality and social psychology, 85(6), 1006.

Wu, C. H., Parker, S. K., \& De Jong, J. P. (2014). Need for cognition as an antecedent of individual innovation behavior. Journal of Management, 40(6), 1511-1534.

Zhou, J. (1998). Feedback valence, feedback style, task autonomy, and achievement orientation: Interactive effects on creative performance. Journal of applied psychology, 83(2), 261.

Zhou, J., \& George, J. M. (2001). When job dissatisfaction leads to creativity: Encouraging the expression of voice. Academy of Management journal, 44(4), 682-696. 